\title{
Adherence by midwives to the Dutch national guidelines on threatened miscarriage in general practice: a prospective study
}

\author{
Margot Fleuren, Richard Grol, Marten de Haan, Dirk Wijkel, Christine Oudshoorn
}

Research Centre Primary/Secondary Health Care,

Academic Hospital of Vrije Universiteit Amsterdam, The Netherlands

Margot Fleuren, social scientist

Dirk Wijkel, social scientist

Centre for Research on Quality in Family Practice, Universities of Nijmegen and Maastricht, The Netherlands

Richard Grol, professor

of general practice

Department of General Practice and

Nursing Home

Medicine, Vrije

Universiteit

Amsterdam, The

Netherlands

Marten de Haan,

professor of general

practice

Midwifery School, Kerkrade, The

Netherlands

Christine Oudshoorn,

director

Correspondence to: Mrs MAH Fleuren, Academic Hospital VU, Research Centre Primary/Secondary Health Care, PO Box 7057, 1007 MB Amsterdam, The

Netherlands.

Accepted for publication 21 February 1997

\begin{abstract}
Objective-To determine the feasibility for midwives to adhere to Dutch national guidelines on threatened miscarriage in general practice.

Design-Prospective recording of appointments by midwives who agreed to adhere to the guidelines on threatened miscarriage. Interviews with the midwives after they had recorded appointments for one year.

Setting-Midwifery practices in The Netherlands.

Subjects-56 midwives who agreed to adhere to the guidelines; 43 midwives actually made records from 156 clients during a period of 12 months.

Main outcome measures-Adherence to each recommendation and reasons for non-adherence.
\end{abstract}

Results-The recommendation that a physical examination should take place on the first and also on the follow up appointment was not always adhered to. Reasons for non-adherence were the midwives' criticism of this recommendation, their lack of knowledge or skills, and the specific client situation. Adherence to a follow up appointment after 10 days, a counselling consultation after six weeks, and not performing an ultrasound scan was low. Reasons for non-adherence were mainly based on the midwives' criticism of these recommendations and reluctance on the part of the client. Furthermore, many midwives did not give information and instructions to the client. It is noteworthy that in $13 \%$ of the cases the midwife's policy was overridden by the obstetrician taking control of the situation after the midwife had requested an ultrasound scan.

Conclusions-Those recommendations in the guidelines on threatened miscarriage that are most often not adhered to should be reviewed. To reduce conflicts about ultrasound scans and referrals, agreement on the policy on threatened miscarriage should be mutually established between midwives and obstetricians.

(Quality in Health Care 1997;6:69-74)

Keywords: guidelines; threatened miscarriage; midwives

A miscarriage in the first trimester of pregnancy is not an uncommon phenomenon. Vaginal bleeding is usually the first sign of a miscarriage, and occurs in about $20 \%$ of all pregnancies before completion of the 16 th week of gestation. ${ }^{1}$ In half of these cases (10\%) the pregnancy ends in a spontaneous miscarriage. ${ }^{23}$ This implies that bleeding in the first trimester also occurs for other reasons. ${ }^{4}$ Vaginal bleeding in pregnant women is consequently often labelled as threatened miscarriage. Most women will seek medical aid when bleeding occurs. Several studies show that threatened miscarriage is a stressful event, and that the psychological sequelae of a miscarriage can be enormous. ${ }^{5-11}$ There is general agreement that therapeutic measures are of no value, but providing information and guidance seem to be important aspects when dealing with threatened miscarriage.

In the Netherlands prenatal, natal, and postnatal care are mainly provided in primary health care by independent midwives and general practitioners (GPs). Only high risk patients are referred to secondary health care: an obstetrician. Symptoms of threatened miscarriage are generally not considered to be a sufficient indication for referral to an obstetrician. Consequently, when there are no complications, the client can remain in the care of the midwife or the GP.

In 1987, the Dutch College of General Practitioners developed a guideline policy programme. One of the first evidence based guidelines to be developed was about threatened miscarriage. ${ }^{12}$ Research showed that, over the years, there had been a shift towards hospital treatment of miscarriage, which generally involves curettage. ${ }^{12}$ This results in treatment of a normally self regulating process. ${ }^{13} \mathrm{~A}$ curettage has both risks and disadvantages. One of the aims of the guidelines on threatened miscarriage is to improve the quality of care by discouraging unnecessary medical intervention. Although these guidelines were developed for general practitioners, the management policy also corresponds with the views of the Midwives' Organisation in The Netherlands, which has recommended its members to adopt these GPs' guidelines because midwives have no specific guidelines. ${ }^{14}$ The guidelines recommend a "wait and see" policy, allowing events to take their normal course. The guidelines include recommendations for history taking and diagnostic and therapeutic management during first and follow up appointments (box).

One of the main problems in the implementation of guidelines in health care is that care providers do not automatically adhere to 
Most important recommendations in the guidelines on threatened miscarriage for general practitioners ${ }^{\star}$

FIRST APPOINTMENT:

GPs should make a diagnosis themselves by carrying out the following examinations:

Percussion and palpation

Speculum examination

Vaginal examination

In the case of a threatened miscarriage

GPs should wait and see, which means:

Explain situation and, if possible, give reassurance

No ultrasound scan

Not refer the patient to an obstetrician GPs should make a follow up appointment after 10 days. However, if the blood loss or pain increases, if the woman has a fever or is anxious, then she should contact the GP immediately.

FOLLOW UP APPOINTMENT:

GPs should carry out the following examinations:

Speculum examination

Vaginal examination

In the case of a complete miscarriage GPs should:

Explain situation

Not use ultrasound scan

Not refer the patient to an obstetrician

In case of an incomplete miscarriagethat is, if the woman is still losing bloodGPs should:

Make an ultrasound scan themselvesthat is, without referring to an obstetrician

In the case of an intact pregnancy GPs should:

Not use ultrasound scan

Not refer the patient to an obstetrician

CARE AFTER MISCARRIAGE:

GPs should plan a counselling consultation six weeks after the miscarriage.

GPs should only refer to an obstetrician after three or more consecutive miscarriages to find out why the woman miscarried.

them. ${ }^{1516}$ For example, problems related to the characteristics of the care provider, the setting in which the care provider works, or the nature of the guidelines may discourage adherence. ${ }^{15-21}$ Research into these problems can lead to identifying interventions which could result in successful implementation. ${ }^{20-24}$ Most of the research in this field has taken place among general practitioners and medical specialists, and yet relatively little is known about other care providers. The results of a survey among midwives showed that most of them accepted the guidelines on threatened miscarriage. ${ }^{25}$ We studied the actual implementation and also the problems midwives experi-

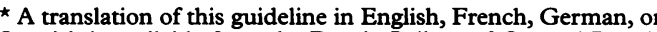
Spanish is available from the Dutch College of General Practitioners, PO Box 3231, 3502 GE Utrecht, The Netherlands. enced in implementation of these guidelines. The results of our study will be used to update the guidelines and, eventually, to amend them for midwives. This research is part of a general evaluation of the guidelines on threatened miscarriage involving GPs, midwives, obstetricians, and patients.

\section{Methods}

SUBJECTS

From a representative group of midwives who had participated in a study on the acceptance of the guidelines on threatened miscarriage, ${ }^{25}$ we selected those $(n=60)$ who reported that they saw more than five women with threatened miscarriage each year and who worked in a midwifery practice where clients could register after six weeks' gestation. We sent them the complete guidelines. Inclusion criteria were that the midwives should accept the guidelines in principle, at least the recommendations regarding referrals, ultrasound scans, and physical examinations, they should be willing to adhere to the guideline for 12 months, and they should record all patients with symptoms of threatened miscarriage. If the midwife worked in a joint practice, all her associates should also meet these criteria. Sixteen midwives and 17 associates met the criteria. Furthermore, 23 midwives (from 13 practices) who had heard about the study also volunteered to participate. We sent these midwives the guidelines and also verified whether they met all the inclusion criteria.

\section{TRAINING}

All midwives received training given by a registered midwife or tutor and a researcher (MF) before the study started. The guidelines were sent to the midwives beforehand, and they were asked to indicate whether they agreed or disagreed with the 17 most important recommendations. Furthermore, they were asked to prepare two case histories and to discuss several cases from their own practice. During the training all recommendations were discussed, including their scientific justification. A great deal of time was spent on discussing the midwife's customary management of threatened miscarriage and determining whether this was in accordance with the guidelines. Strategies for adherence were discussed in cases in which the actual management seemed to differ from the policy outlined in the guidelines. Furthermore, the midwives were asked questions relating to their personal and practice characteristics - for example, their age and whether they were associated with other midwives.

\section{PROCEDURE}

From 1994 to 1995 a prospective study, based on midwives' records, was carried out. For a period of 12 months, the 56 midwives recorded all clients with blood loss or pain before completion of the 16th week of gestation, or showing other symptoms that might indicate threatened miscarriage-such as not feeling pregnant any more, fear of miscarriage, or absence of fetal heartbeat on a routine 
ultrasound scan. Only new episodes were recorded. The midwives recorded every appointment during surgery hours, every phone call, and every visit on a special record form. Among the items recorded were history taking, diagnostics, diagnosis, treatment, and policy on follow up care. Immediately after every contact the midwives completed the record form and sent it to the researcher, retaining a copy for themselves. Every three months all midwives who had not recorded clients during the previous three months were contacted by telephone to ask what the reasons were.

\section{INTERVIEW}

At the end of the 12 month period every midwife who took part in the study was interviewed. Every client seen by the midwife was discussed in a structured telephone interview supported by the copies of the record forms and the client's charts. The midwives were asked to give their reasons for not adhering to the recommendations. Two researchers who conducted the interviews were given an interview training beforehand by MF. This included information about the coding system that would be used to categorise reasons for non-adherence. MF identified the recommendations the midwife had not adhered to for each client. These were discussed with the interviewer before each interview took place. All answers given by the midwife were noted and transcribed directly after the interview.

VARIABLES AND ANALYSES

Two researchers analysed adherence to the guidelines by means of a code list, developed by the two researchers and two GPs on the basis of the guidelines. Recommendations were adapted to allow for measurement. For instance, if the first appointment was a telephone consultation, subsequent appointments within 48 hours were considered to be part of the first appointment; if the first appointment was during surgery hours or during a home visit, subsequent appointments within 24 hours were also considered to be part of this first appointment. The two researchers independently coded the recommendations of 30 randomly chosen record forms to assess their reliability. A $\kappa$ coefficient of agreement $\geq 0.76$ was obtained (Cohen's $\kappa$ adjusted for change).

The reasons for non-adherence that the midwives gave during the interview were divided into four main categories, ${ }^{15-17}$ relating to: (a) the midwife herself: lack of knowledge or skills; general attitude-for example, tendency to refer clients in general or reverting to old routines-criticism of specific recommendations, specific client situation; $(b)$ other care providers: colleague midwives, GPs, obstetricians; (c) the client: wishes or pressure, compliance; (d) the setting: organisational problems-for example, lack of ultrasound scanning equipment.

The midwives' answers were assigned by three researchers to a specific category on a consensus basis. Only those categories are pre- sented in which there was a reason for not adhering to the related recommendation; the number of reasons within one category is not presented. Furthermore, only those reasons for not adhering to the recommendations which related to diagnostics and policy were recorded, as these seemed to be the most important. Many midwives worked in a joint practice, meaning that the woman might see more than one midwife during the entire episode. Therefore, the results are presented at client level, but adherence was also examined at midwife level.

\section{Results}

In total, 56 midwives were willing to participate in the study. Of these, 43 midwives recorded 156 clients with symptoms of threatened miscarriage: a mean of 3.6 clients per midwife. Five midwives did not submit client records because of illness, another five because of work stress, and a further three midwives did not see any clients with symptoms of threatened miscarriage. The breakdown in terms of sex, age, and membership of the Midwives' Organisation showed that the 43 midwives corresponded to the national midwife population. ${ }^{26}$ However, on average fewer midwives from single practices were involved in the study: $7 \%$ in the study group compared with $24 \%$ at national level $\left(\chi^{2}\right.$, $P<0.01)$.

The mean (SD; range) age of the clients was $29.3(4.3 ; 16-39)$ years, and the duration of pregnancy at the first appointment was 10.4 $(2.3 ; 4-16)$ weeks. Of the clients $62 \%$ had been pregnant before and $18 \%$ had already had one or more miscarriages. The main reasons why clients contacted the midwife were blood loss $(87 \%)$, anxiety or not feeling pregnant any more $(30 \%)$, pain $(21 \%)$, and no heartbeat on (routine) ultrasound scan (11\%). The number of appointments per client was $3.6(1.6 ; 1-9)$.

\section{ADHERENCE TO THE GUIDELINES}

Many recommendations were followed (table 1), but adherence was low for physical examinations at both first and follow up appointments, especially for a speculum examination. Ultrasound scans were also often made, although they are not recommended in the guidelines. Follow up appointments were often not made within the advised period of 10 days; in $69 \%$ of the clients the midwife made an appointment within seven days and in $31 \%$ either after 15 days or not at all. Some recommendations on the provision of information and instructions were not followed-for example, only half of the clients received information about the cause or the possible treatment of threatened miscarriage, and very few clients were told to contact the midwife if they had a fever or if they were worried. Finally, in most cases, counselling consultations after the miscarriage did not take place within the advised period of six weeks.

REASONS FOR NON-ADHERENCE

Table 2 shows the categories of reasons for non-adherence to the recommendations. The 
Table 1 Percentage of clients for whom the midwives adhered to the recommendations for the first and follow up appointments $(n=156)$

\begin{tabular}{|c|c|c|}
\hline & Intervention & Adherence \\
\hline Client history questions & $\begin{array}{l}\text { + Feeling pregnant } \\
+ \text { Volume of blood loss } \\
\text { + Duration of blood loss } \\
\text { + Nature of blood loss } \\
\text { + Loss of tissue } \\
\text { + Duration of pain } \\
\text { + Nature of pain } \\
\text { + Feeling ill } \\
\text { + Having a temperature }\end{array}$ & $\begin{array}{l}71 \\
99 \\
98 \\
99 \\
55 \\
92 \\
93 \\
67 \\
51\end{array}$ \\
\hline Diagnostics first appointment & $\begin{array}{l}\text { + Percussion or palpation } \\
\text { + Speculum examination } \\
\text { + Vaginal examination } \\
\text { - Ultrasound scan }\end{array}$ & $\begin{array}{l}59 \\
17 \\
44 \\
71\end{array}$ \\
\hline Information first appointment & $\begin{array}{l}+ \text { Cause } \\
+ \text { Course } \\
+ \text { Treatment }\end{array}$ & $\begin{array}{l}49 \\
85 \\
46\end{array}$ \\
\hline Policy first appointment & $\begin{array}{l}\text { - Referral to obstetrician } \\
\text { - Medication } \\
\text { - Curettage } \\
\text { + Follow up between } 7-14 \text { days * }\end{array}$ & $\begin{array}{l}92 \\
99 \\
98 \\
32\end{array}$ \\
\hline Instructions first appointment & $\begin{array}{l}\text { - Bed rest } \\
\text { - Collect blood clots } \\
\text { + Appointment if pain increases } \\
\text { + Appointment if blood loss increases } \\
\text { + Appointment if having a fever } \\
\text { + Appointment if worried }\end{array}$ & $\begin{array}{l}96 \\
99 \\
71 \\
80 \\
28 \\
59\end{array}$ \\
\hline Diagnostics follow up 7-14 days & $\begin{array}{l}+ \text { Percussion or palpation } \\
+ \text { Speculum examination } \\
+ \text { Vaginal examination }\end{array}$ & $\begin{array}{l}36 \\
23 \\
34\end{array}$ \\
\hline Diagnostics follow up appointments & - Ultrasound scan $t$ & 77 \\
\hline Policy follow up appointments & $\begin{array}{l}\text { - Medication } \dagger \\
\text { - Referral to obstetrician } \dagger\end{array}$ & $\begin{array}{l}96 \\
88\end{array}$ \\
\hline Counselling after miscarriage & + Took place 3-6 weeks afterwards $\ddagger$ & 13 \\
\hline
\end{tabular}

+ Is advised unless there are complications as specified in the guideline; - is not advised unless there are complications as specified in the guideline.

${ }^{\star} \mathrm{n}=149 ; 7$ clients are excluded, as their first appointment was within 7-14 days after the symptoms started.

$\dagger \mathrm{n}=137 ; 19$ clients had no follow up appointments.

$\ddagger \mathrm{n}=119 ; 37$ clients had an intact pregnancy. totals show that criticism of a specific recommendation was mentioned most often, then the situation of the specific client, lack of knowledge or skills, and the client's wishes. However, in each recommendation this sequence of the most often mentioned reasons differs. Reasons for not carrying out a physical examination at the first appointment were mainly based on the midwife's criticism of the recommendations-for example, "it provides no additional information for the client's case history" or "not necessary because I use a doptone to find out whether the fetus is still alive". A second reason was the situation of the specific client. In this respect the midwives mainly said that there was a clear diagnosis because the client had been given an ultrasound scan. In terms of general attitude, many reported that they never carried out a physical examination because they thought that it was embarrassing for the client. Furthermore, many midwives said that they were not able to feel anything at this stage of pregnancy, or that they did not trust the findings (lack of knowledge or skills). Finally, for failure to carry out a speculum examination, midwives reported that they had either not taken a speculum with them during a home visit or did not even have a speculum (organisational problem). Of the midwives, $78 \%$ had not carried out vaginal examinations and $95 \%$ had not carried out speculum examinations during the first contact with at least one of their clients.

Reasons for not carrying out physical examinations during follow up appointments were related to the midwife's criticism-for example, "If severe blood loss has stopped, the diagnosis is clear"-and to the specific client situation-such as, "an ultrasound scan was made, so the diagnosis was clear". Furthermore, interference from the obstetrician was often mentioned: "the obstetrician had taken control after making an ultrasound

Table 2 Number of reasons the midwives gave for not adhering to the recommendations for the first and follow up appointments *

\begin{tabular}{|c|c|c|c|c|c|c|c|c|c|c|}
\hline & \multicolumn{4}{|l|}{ Midwives } & \multicolumn{2}{|c|}{ Care providers } & \multicolumn{2}{|c|}{ Clients } & \multicolumn{2}{|l|}{ Setting } \\
\hline & $\begin{array}{l}\text { Knowledge } \\
\text { or skills }\end{array}$ & $\begin{array}{l}\text { General } \\
\text { attitude }\end{array}$ & $\begin{array}{l}\text { Criticism } \\
\text { recommendation }\end{array}$ & $\begin{array}{l}\text { Specific } \\
\text { client } \\
\text { situation }\end{array}$ & Midwife & $\begin{array}{l}\text { GPor } \\
\text { obstetrician }\end{array}$ & Wish & Compliance & Organisation & Total \\
\hline \multicolumn{11}{|l|}{ Diagnostics first appointment: } \\
\hline $\begin{array}{l}\text { + Percussion or palpation } \\
\text { + Speculum examination }\end{array}$ & $\begin{array}{l}18 \\
19\end{array}$ & $\begin{array}{l}1 \\
36\end{array}$ & $\begin{array}{l}15 \\
41\end{array}$ & $\begin{array}{l}21 \\
23\end{array}$ & $\begin{array}{l}0 \\
0\end{array}$ & $\begin{array}{l}0 \\
0\end{array}$ & $\begin{array}{l}2 \\
5\end{array}$ & $\begin{array}{l}2 \\
2\end{array}$ & $\begin{array}{l}4 \\
29\end{array}$ & $\begin{array}{l}63 \\
155\end{array}$ \\
\hline $\begin{array}{l}\text { + Speculum examination } \\
\text { + Vaginal examination }\end{array}$ & 17 & 17 & $\begin{array}{l}41 \\
31\end{array}$ & 26 & 0 & 0 & 3 & $\begin{array}{l}2 \\
2\end{array}$ & $\begin{array}{l}29 \\
4\end{array}$ & $\begin{array}{l}155 \\
100\end{array}$ \\
\hline - Ultrasound scan & 15 & 1 & 19 & 6 & 0 & 2 & 15 & 0 & 0 & 58 \\
\hline \multicolumn{11}{|l|}{ Policy first appointment: } \\
\hline - Referral to obstetrician & 0 & 0 & 4 & 0 & 0 & 2 & 5 & 0 & 1 & 12 \\
\hline - Curettage & 0 & 0 & 0 & 0 & 0 & 1 & 2 & 0 & 0 & 3 \\
\hline+ Follow up 7-14 days & 0 & 4 & 37 & 35 & 0 & 5 & 12 & 1 & 3 & 97 \\
\hline \multicolumn{11}{|l|}{ Diagnostics 7-14 days: } \\
\hline + Percussion or palpation & 6 & 2 & 31 & 28 & 2 & 15 & 2 & 3 & 3 & 92 \\
\hline + Speculum examination & 8 & 13 & 44 & 27 & 2 & 15 & 2 & 3 & 7 & 121 \\
\hline + Vaginal examination & 8 & 11 & 33 & 27 & 2 & 15 & 2 & 3 & 3 & 104 \\
\hline \multicolumn{11}{|l|}{$\begin{array}{l}\text { Diagnostics follow up } \\
\text { appointments: }\end{array}$} \\
\hline - Ultrasound scan & 2 & 0 & 11 & 4 & 0 & 1 & 16 & 0 & 0 & 34 \\
\hline $\begin{array}{l}\text { Policy follow up appointments: } \\
\text { - Referral to obstetrician }\end{array}$ & 0 & 0 & 6 & 1 & 1 & 0 & 9 & 0 & 1 & 18 \\
\hline $\begin{array}{l}\text { Counselling after miscarriage: } \\
\text { + Took place } 3-6 \text { weeks }\end{array}$ & & & & & & & & & & \\
\hline afterwards & 4 & 3 & 63 & 0 & 0 & 0 & 21 & 8 & 2 & 101 \\
\hline Total & 97 & 88 & 335 & 198 & 7 & 56 & 96 & 24 & 57 & 958 \\
\hline
\end{tabular}

* More than one reason could be mentioned.

+ Is advised unless there are complications as specified in the guideline; - is not advised unless there are complications as specified in the guideline. 
scan, so there was no point in carrying out the examinations". Between $75 \%$ and $93 \%$ of the midwives did not adhere to these three recommendations during the follow up appointments with at least one of their clients.

Reasons for making an ultrasound scan were related to the midwife's lack of knowledge or skills-for example, "I don't know how to interpret the findings of the physical examinations, so I make an ultrasound scan just to be sure", or related to criticism-for example, "clients should have an ultrasound scan to reassure them". Finally, they often mentioned that the client had requested an ultrasound scan (client's wish). Of the midwives, $58 \%$ had not adhered to the recommendation concerning ultrasound scans with at least one of their clients.

One of the reasons for not planning a follow up appointment was the midwife's criticism that: "the client should contact me sooner for reassurance" or "a follow up is not necessary when blood loss has stopped". The situation of the specific client was also mentioned as a reason-for example, for coming back immediately after an ultrasound scan had been made. Finally, the client's wish to return earlier for reassurance also played a part. Most midwives (88\%) had not adhered to this recommendation with at least one of their clients.

If there was no counselling consultation, it was generally because of a midwife's criticism-such as, "the six week period is too long" or "I don't think it's my job". But the client's unwillingness was also mentioned. Of the midwives, $87 \%$ had not adhered to the recommendation for a counselling consultation with at least one of their clients.

In 20 cases, the midwife's policy had been overridden. In 18 cases in which the midwife had requested an ultrasound scan on her own authority, without a referral, the obstetrician had still assumed control. In another two cases, either a colleague midwife, acting as a locum, or the GP had made a referral which was not necessary in the opinion of the midwife.

\section{Discussion}

It can be concluded from our study that the recommendations relating to diagnostics and policy in the guidelines on threatened miscarriage are not always adhered to. This applies in particular to: physical examinations at both first and follow up appointments; planning a follow up appointment after 10 days; and not making ultrasound scans. Between $58 \%$ and $95 \%$ of the midwives did not adhere to these recommendations with at least one of their clients. Reasons for non-adherence are mainly related to the midwives themselvesfor example, they were critical of the specific recommendations. The client's wishes were also involved, especially for ultrasound scans.

The recommended diagnostics and policy are important in the detection of complications-such as an ectopic or molar pregnancy. However, medical intervention cannot prevent a woman from having a miscarriage. Therefore, providing information and guidance are important aspects in the treatment of threatened miscarriage. It is noteworthy that only half of the clients received information about the cause and possible treatment of threatened miscarriage during the first appointment. Many clients were also not told to contact the midwife if they were worried. Furthermore, in $87 \%$ of the cases there was no counselling consultation after six weeks: $87 \%$ of the midwives had not adhered to this recommendation with at least one of their clients. Although some midwives did hold a counselling consultation within three weeks because they thought the six week period was too long, others thought it was not their job or that the client did not want it.

Several critical observations should be made about this research. In the first place, the participating midwives may not be completely representative of the national midwife population because they were self selected as having accepted the guidelines in principle. However, the necessity for the midwives to be a representative group does not seem to be crucial to determine the feasibility of the guidelines. If these motivated midwives are not able to adhere to the guideline, other less motivated midwives will not be able to either. This implies that, at national level, adherence may even be lower, due to non-acceptance. Secondly, the fact that many reasons for non-adherence were related to the midwives themselves may be due to the design of the study. If the client had been interviewed instead of the midwife, this would probably have shown more client related reasons. Finally, the interviews at the end of the 12 month period might have caused some recall problems. However, the midwives referred to the copies of the record forms and the client charts during the interview, so they were easily able to recall the client's situation and the reasons why they had not adhered to the specific recommendations.

Bearing in mind that the guidelines were developed for general practitioners, some problems with adherence might have been anticipated as midwives will not automatically accept and implement these GPs' guidelines. The Midwives' Organisation in The Netherlands decided not to amend the guidelines but to advise its members to adopt them. However, the results of this study will be used to update the guidelines and, eventually to amend them for midwives. Firstly, we suggest that a review should be made of those recommendations that were not widely accepted by the midwives - for example, the 10 day period for the follow up appointment or the six week period for a counselling consultation. Perhaps both periods should be shorter. With regard to criticism of the other recommendations, it is still not certain whether, for example, ultrasound scans should be made, because many midwives are not used to carrying out certain physical examinations, or whether they should learn how to carry them out. Secondly, as threatened miscarriage is quite a stressful event for most women, and no medical treatment is available, midwives should pay 
more attention to the recommendations about the provision of information, instructions, and counselling. Thirdly, improved collaboration between midwives and obstetricians is certainly necessary. We suggest that at national level the organisations for midwifery and obstetrics should agree on a policy on threatened miscarriage to reduce conflicts at local level about ultrasound scans and referrals. Finally, the number of ultrasound scans that are made solely to reassure the client should be reduced. There should be a balance between the client's wishes on the one hand, and medically unnecessary ultrasound scans on the other. Informing the client about the pros and cons of ultrasound scans may contribute to this balance, and for this reason we recommend future research into the clients' views and wishes with regard to policies on threatened miscarriage. Implementation programmes should certainly focus directly on midwives as well as on education of clients and collaboration with other disciplines. Multidisciplinary guidelines developed in collaboration with GPs, midwives, obstetricians, and patients would be the optimal approach.

1 Bennebroek Gravenhorst J, Christiaens GCML, Kanhai $\mathrm{HHH}$, Treffers PE. Aan de zwangerschap gebonden afwijkingen (Abnormalities relating to pregnancy). In: Treffers PE, Heintz APM, Keirse MJNC, Rolland R, eds Obstetrie en gynaecologie. De voortplanting van de mens [Obstetric and gynaecology. Reproduction of humans]. Utrecht: Bunge, 1993:226-99.

2 Miller JF, Williamson E, Glue J, Gordon YB, Grudzinskas JG, Sykes A. Fetal loss after implantation. A prospective study. Lancet 1980;ii:554-6.

3 Wilcox AJ, Weinberg CR, O'Connor JF, Baird DD, Schlatterer JP, Canfield RE, et al. Incidence of early loss of pregterer JP, Canfield RE, et al. Incidence of

4 Chamberlain G. Vaginal bleeding in early pregnancy I. BMF 1991;302:1141-3.

5 Friedman T. Women's experiences of general practitioner management of miscarriage. f $R$ Coll Gen Pract 1989; 39:456-8
6 Friedman T, Gath D. The psychiatric consequences of spontaneous abortion. Br F Psychiatry 1989;155:810-3

7 Manca DP, Bass MJ. Women's experience of miscarriage. Can Fam Physician 1991;37:1871-7.

8 Conway K. Miscarriage. I Psychosom Obstet (ivnaecol 1991; 12:121-31.

9 Rosenfeld JA. Bereavement and grieving after spontaneous abortion. Am Fam Physician 1991;43:1679-84

10 Neugebauer R, Kline J, O'Connor P, Schrout P, Johnson J, Skodol A, et al. Determinants of depressive symptoms in the early weeks after miscarriage. Am F Public Health 1992 82:1332-9.

11 Janssen HJEM. A longitudinal prospective study of the psychological impact of pregnancy loss on women [thesis]. Nijmegen: Katholieke Universiteit Nijmegen 1995.

12 Flikweert S, Ligtenberg WJJ, Sips AJBI. Standaard (dreigende) miskraam (Guideline on (threatened) miscarriage). Huisarts en Wetenschap 1989;32:138-43.

13 Nielsen S, Hahlin M. Expectant management of first trimester spontaneous abortion. Lancet 1995;345:84-6.

14 Van der Esch L. Beleidsadvies bij dreigende miskraam (policy advice on threatened miscarriage). Tijdschrift voor Verloskundigen 1989;14:228.

15 Grol R. Implementing guidelines in general practice care. Quality in Health Care 1992;1:184-91.

16 Lomas J. Teaching old (and not so old) docs new tricks: effective ways to implement research findings. In: Dun EV, Norton PG, Stewart M, Tudiver F, Bass MJ, eds. Disseminating research/changing practice. Iondon: Sage, 1994:1-18.

17 Grol RTPM, Van Everdingen JJE, Casparic AF. Invoering van richtlijnen en veranderingen (The implementation of guidelines and change). Utrecht: De Tijdstroom, 1994

18 Grimshaw J, Freemantle N, Wallace S, Russell I, Hurwitz B, Watt I, et al. Developing and implementing clinical practice guidelines. Quality in Health Care 1995;4:55-64.

19 Conroy M, Shannon W. Clinical guidelines: their implemen tation in general practice. Br $\mathcal{F}$ Gen Pract 1995;45:371-5.

20 Woolf SH. Practice guidelines: what the family physician should know. Am Fam Physician 1995;51:1455-63.

21 Kanouse DE, Kallich JD, Kahan JP. Dissemination of effectiveness and outcomes research. Health Policy 1995 $4: 167-92$

22 Grol R. Development of guidelines for general practice care. Br f Gen Pract 1993;43:146-51.

23 Norr KF. Using quantitative and qualitative methods to assess impact on practice. In: Dunn EV, Norton PG, Stewart M, Tudiver F, Bass MJ, eds. Disseminating research/changing practice. London: Sage, 1994:109-26.

$24 \mathrm{Lohr}$ KN. Guidelines for clinical practice: applications for primary care. Int $\mathcal{F}$ Qual Health Care 1994;6:17 25.

25 Fleuren M, Grol R, De Haan M, Wijkel D. Care for the imminent miscarriage by midwives and GPs. Fam Prac 1994;11:275-81.

26 NIVEL. Registratie van verloskundigen. Peiling 1994 (Statistical data from midwife records for 1994). Utrecht: NIVEL, 